\title{
Cystic fibrosis screening: a fetus with hyperechogenic bowel may be the index case
}

Françoise Muller, Marc Dommergues, Brigitte Simon-Bouy, Claude Ferec, Jean-François Oury, Marie-Cécile Aubry, Roger Bessis, Edith Vuillard, Erick Denamur, Thierry Bienvenu, Jean-Louis Serre

Biochimie, Hôpital Ambroise Paré, 92104 Boulogne, France F Muller

Médecine Foetale, Maternité A Beclere, Paris, France A Beclere

M Dommergues

SESEP, Université Versailles

Saint-Quentin, France

B Simon-Bouy

Biogénétique, Brest, France

C Ferec

Médecine Foetale, Hôpital Robert Debré, Paris, France

J-F Oury

Echographie, Hôpital Necker, Paris, France M-C Aubry

Echographie, Centre Odéon, Paris, France R Bessis

Echographie, Hôpital Robert Debré, Paris,

France

E Vuillard

Biochimie Génétique, Hôpital Robert Debré, Paris, France

E Denamur

Biochimie Génétique, Hôpital Cochin, Paris, France

T Bienvenu

\section{Laboratoire de} Cytogénétique et Génétique Moléculaire Humaine, Université Versailles

Saint-Quentin, France J-L Serre

Correspondence to: Dr Muller.

Received 10 September 1997 Revised version accepted for publication 20 January 1998

\section{Abstract}

Background-The potential of hyperechogenic fetal bowel to act as a hallmark for prenatal cystic fibrosis screening in the general population is controversial. Methods-Our goal was to evaluate the incidence of cystic fibrosis in 209 fetuses with hyperechogenic bowel diagnosed at routine ultrasonography and with no family history of cystic fibrosis. The diagnosis of cystic fibrosis was based on prenatal screening for the eight mutations most frequently observed in France $(\Delta F 508$, $\Delta I 507, \quad 1717-1 G \rightarrow A, \quad G 542 X, \quad G 551 D$, R553X, W1282X, N1303K) and at postnatal follow up.

Results-The overall incidence of cystic fibrosis was $7 / 209$ (3.3\%) which is 84 times the estimated risk of CF in the general population (1/2500). Of these seven cases, six were diagnosed prenatally based on DNA analysis $(\Delta F 508 / \Delta F 508, n=5 ; \Delta F 508$ I G542X, $n=1)$. One case in which only one mutation had been recognised was diagnosed clinically after birth ( $\triangle F 508$ ) unidentified mutation). Of the seven cases, none was diagnosed at 16-19 weeks, four at 16-24 weeks, and three after this. The incidence of heterozygous fetuses (15/ $209,7 \%$ ) was not significantly higher than the $5 \%$ expected in the general population. The mutations involved in these heterozygous cases were $\Delta F 508(n=13), G 542 X$ $(n=1)$, and G551D $(n=1)$.

Conclusions-Screening for cystic fibrosis should be offered to families in which fetal hyperechogenic bowel is diagnosed at routine ultrasonography. This underlines the need to review genetic counselling in this situation where the fetus is the index case for a genetic disease.

$(\Im$ Med Genet 1998;35:657-660)

Keywords: cystic fibrosis; prenatal diagnosis; ultrasound; hyperechogenic fetal bowel

Hyperechogenic fetal bowel is recognised at routine ultrasound in about $0.6 \%$ of pregnancies $^{1-5}$ and is associated with a variety of fetal abnormalities. ${ }^{6-12}$ Hyperechogenic fetal bowel is considered to be suggestive of cystic fibrosis (CF), but this remains controversial because of the lack of extensive screening for CF mutations ${ }^{510^{13-15}}$ in large populations.

Our goal was to evaluate the incidence of CF in fetuses with hyperechogenic fetal bowel in order to establish the usefulness of genetic testing for cystic fibrosis transmembrane conductance regulator (CFTR) mutations in this population. Therefore, a prospective study based on prenatal screening for CFTR mutations and postnatal follow up was conducted on cases referred to our laboratory for karyotyping following prenatal diagnosis of hyperechogenic fetal bowel at routine ultrasonography.

\section{Materials and methods}

From 1990 to 1994,214 cases were referred to our laboratory because hyperechogenic fetal bowel had been diagnosed by routine ultrasound. Each couple was interviewed by a genetic counsellor to rule out any family history of CF. No consanguinity was observed.

Sonograms were recorded by 36 sonographers from 16 centres. The fetal bowel was considered as hyperechogenic when its echogenicity was broadly similar to, or greater than, that of the surrounding bone, corresponding to grade II described by MacGregor et al, ${ }^{16}$ regardless of the shape of the echogenic mass, which was either round and well limited or had the sinuous appearance of an intestinal loop. Occasionally, hyperechogenicity was associated with images suggestive of bowel dilatation. No associated malformation was detected during the level III ultrasound examination performed at the time of amniocentesis. In 83 cases, hyperechogenic fetal bowel was diagnosed before 20 weeks of gestation and in 131 cases after this.

Karyotyping was performed on amniotic fluid cells in 213 cases and on fetal blood cells in one case (at 37 weeks).

Maternal serum screening for toxoplasmosis and cytomegalovirus infection was performed in every case and viral cultures of amniotic fluid were performed when appropriate.

Screening for CF was based on the prenatal detection of CFTR mutations and on postnatal follow up. Prenatal screening for CFTR mutations was performed on fetal cells, or on parental blood cells, or on both. In all cases screening covered at least the eight mutations most frequently observed in France and North America, that is, $\Delta \mathrm{F} 508, \Delta \mathrm{I} 507,1717-1 \mathrm{G} \rightarrow \mathrm{A}$, G542X, G551D, R553X, W1282X, and N1303K. ${ }^{17}{ }^{18}$ DNA was extracted from cultured amniotic cells or parental lymphocytes or both. After polymerase chain reaction (PCR) amplification of the sequence adjacent to the $\Delta$ F508 mutation, the mutation was disclosed by polyacrylamide gel electrophoresis (PAGE). Other mutations were shown by ASO (allele 
Table 1 Fetal and parental mutations of cystic fibrosis and pregnancy outcome in 209 cases of hyperechogenic fetal bowel

\begin{tabular}{|c|c|}
\hline Prenatal genetic screening & Outcome \\
\hline No CFTR mutation detected $(n=188)$ * & $\begin{array}{l}\text { Normal infant }(n=148) \\
\text { IUD or miscarriage }(n=14) \\
\text { Trisomy } 21 \text {, TOP }(n=3) \\
\text { Tetrasomy } 12 p \text {, TOP }(n=1) \\
\text { CMV/toxoplasmosis infection, TOP }(n=7) \\
\text { Multiple malformations, TOP }(n=2) \\
\text { Neonatal death unrelated to CF }(n=3) \\
\text { Bowel atresia }(n=8) \\
\text { Neonatal gastric haemorrhage }(n=1) \\
\text { Sudden infant death syndrome }(n=1)\end{array}$ \\
\hline \multicolumn{2}{|l|}{ Heterozygous CFTR mutation detected $(n=15)$} \\
\hline Fetus $\Delta \mathrm{F} 508 / \mathrm{x}(\mathrm{n}=13)$ & $\begin{array}{l}\text { Normal infant }(n=5) \\
\text { IUD }(n=3) \\
\text { Digestive atresia, surgical treatment }(n=3) \\
\text { TOP, fetal ascites }(n=1) \\
\text { Cystic fibrosis with meconium ileus at birth }(n=1)\end{array}$ \\
\hline $\begin{array}{l}\text { Fetus G551D/x, father } x / x \text {, mother G551D/x }(n=1) \\
\text { Fetus G542X/x, father G542X/x, mother } x / x(n=1)\end{array}$ & $\begin{array}{l}\text { Normal infant }(n=1) \\
\text { Normal infant }(n=1)\end{array}$ \\
\hline \multicolumn{2}{|l|}{ Homozygous CFTR mutation detected $(n=6)$} \\
\hline Fetus $\Delta F 508 / \Delta F 508$, father $\Delta F 508 / x$, mother $\Delta F 508 / x(n=5)$ & $\begin{array}{l}\text { CF affected: TOP }(n=2) \\
\text { CF affected: IUD }(n=1) \\
\text { CF affected: one neonatal death, one survivor }(n=2)\end{array}$ \\
\hline Fetus $\Delta F 508 / G 542 X$, father G542X/x, mother $\Delta F 508 / x(n=1)$ & CF affected: TOP $(n=1)$ \\
\hline
\end{tabular}

$\mathrm{CF}=$ cystic fibrosis; $\mathrm{x} / \mathrm{x}=$ no $\mathrm{CFTR}$ mutation detected; $\mathrm{CFTR}=\mathrm{CF}$ transmembrane regulator; $\mathrm{TOP}=$ termination of pregnancy; IUD=intrauterine death; $\mathrm{CMV}=$ cytomegalovirus infection.

$\star$ Detail of screening strategy in unaffected fetuses: fetus not screened, father $x / x$, mother $x / x(n=78)$; fetus $x / x$, parents not studied $(\mathrm{n}=75)$; fetus $\mathrm{x} / \mathrm{x}$, father $\mathrm{x} / \mathrm{x}$, mother $\mathrm{x} / \mathrm{x}(\mathrm{n}=31)$; fetus $\mathrm{x} / \mathrm{x}$, father $\Delta \mathrm{F} 508 / \mathrm{x}$, mother $\mathrm{x} / \mathrm{x}(\mathrm{n}=1)$; fetus $\mathrm{x} / \mathrm{x}$, father $\mathrm{x} / \mathrm{x}$, mother $\Delta \mathrm{F} 508 / \mathrm{x}$ $(\mathrm{n}=3)$.

specific oligonucleotides) or enzymatic digestion and PAGE using standard procedures. Denaturing gradient gel electrophoresis (DGGE) was used to screen for other cystic fibrosis mutations, in particular when a heterozygous fetus was diagnosed. ${ }^{19}$

All neonates were examined by a paediatrician at birth, at 1 month, and at 3 months. All heterozygous babies were screened at birth for cystic fibrosis by immunoreactive trypsin assay and a sweat test was performed at 3 months.

\section{Results}

Of the 214 cases of hyperechogenic fetal bowel screened for at least eight CFTR mutations, five were lost to follow up. Fetal and parental $\mathrm{CF}$ mutations and outcomes of the remaining 209 cases are summarised in table 1. Gestational ages at which amniocentesis was performed are shown in table 2 .

OUTCOME OF PREGNANCIES

There were 18 intrauterine deaths (one cystic fibrosis) and 17 terminations of pregnancy (three Down's syndrome, one tetrasomy 12p,

Table 2 Gestational age at amniocentesis in hyperechogenic fetal bowel cases and CF affected cases

\begin{tabular}{lcl}
\hline Gestational age * $^{*}$ & No of cases & $\begin{array}{l}\text { No of } C F \\
\text { affected cases }\end{array}$ \\
\hline $15-16$ & 15 & \\
$17-18$ & 43 & \\
$19-20$ & 42 & 1 \\
$21-22$ & 34 & \\
$23-24$ & 32 & 3 \\
$25-26$ & 15 & 1 \\
$27-28$ & 14 & 1 \\
$29-30$ & 6 & \\
$31-32$ & 3 & \\
$33-34$ & 3 & 1 \\
$35-36$ & 1 & 7 \\
37 & 1 & \\
Total & 209 &
\end{tabular}

*Amniotic fluid was sampled within one week following the sonographic diagnosis of hyperechogenic bowel.

In France, routine ultrasound examination is usually performed once in the second trimester $(22 \pm 2 \mathrm{wk})$ and once in the third trimester $(32 \pm 2 \mathrm{wk})$. This accounts for the scattered distribution of gestational age. one toxoplasmosis, six cytomegalovirus infection, two multiple malformation syndrome, three cystic fibrosis, and one heterozygous $\Delta$ F508 complicated by fetal ascites). Four neonatal deaths occurred (one hyaline membrane disease, one eclampsia, one cystic fibrosis, and one unidentified metabolic disease). Of 170 infants who survived the neonatal period, 155 were normal at clinical follow up while 15 had an abnormal outcome, including 11 bowel atresia, one neonatal gastric haemorrhage, one sudden infant death syndrome, and two cystic fibrosis with meconium ileus.

\section{CFTR MUTATIONS}

Among the 188 fetuses in whom no CFTR mutation was identified, 159 were alive three or more months postnatally. None had symptoms suggestive of CF. Perinatal or infant death occurred in 29 cases (termination of pregnancy for fetal anomaly in 13 cases, in utero death in 14 cases, and neonatal death in two). In none of these were postmortem findings suggestive of CF.

Six fetuses were homozygous for CFTR mutations (five $\Delta F 508 / \Delta F 508$, one compound heterozygous $\Delta \mathrm{F} 508 / \mathrm{G} 542 \mathrm{X}$ ). Of these, there were three terminations of pregnancy (TOP), one intrauterine death (IUD) related to maternal eclampsia, and two live births.

Fifteen fetuses were found to be heterozygous for one of the CFTR mutations tested: $13 \Delta$ F508, one G542X, and one G551D. At least 15 of the more common cystic fibrosis mutations in France were screened for in these cases and none was identified. In these 15 cases, there were one TOP (intrauterine ascites diagnosed at sonographic follow up), three IUD, and 11 live births. Of the latter infants, three had bowel atresia without CF (normal sweat test), seven were symptom free and had a normal sweat test, and one had CF (meconium ileus and abnormal sweat test). In the latter case, two other sequence variations in the 
CFTR gene were recognised postnatally based on DGGE, but it was impossible to distinguish between polymorphism and CF related mutations.

In summary, out of 209 cases of hyperechogenic fetal bowel, 155 cases $(72 \%)$ had a normal outcome and CF was diagnosed in seven cases $(3.3 \%$ ), none before 20 weeks, four during the period 20-24 weeks, and three after. Fifteen fetuses $(7 \%)$ were heterozygous, a frequency not statistically different from that in the general population (5\%).

\section{Discussion}

Until recently, prenatal diagnosis of genetic disorders was based on the identification of an increased genetic risk calculated on the basis of pedigree analysis. However, this strategy cannot prenatally identify new cases of CF where there is no family history.

Programmes have been designed to identify couples at risk based on parental screening for the most frequent mutations of the CFTR gene. ${ }^{20-24}$ However, their potential clinical value should be weighed against their cost and the ethical limitations inherent in population genetic screening. In countries in which routine obstetrical ultrasound is implemented, fetal morphological markers suggestive of a genetic disorder can be diagnosed unexpectedly in a low risk pregnancy, such as hyperechogenic fetal bowel. Many clinical problems are raised by this new approach to genetic diagnosis, in which the index case is not yet born.

Indeed, the association between hyperechogenic bowel and CF remained questionable in early reports S $^{10141525}$ owing to the lack of extensive DNA screening in large patient populations and to the absence of adequate postnatal follow up.

Our results show that in the clinical setting in which the study was conducted, the incidence of CF was significantly higher in fetuses with hyperechogenic bowel than in the general population, in spite of the absence of any family history. Therefore our data can be used to evaluate the cost effectiveness of CFTR mutation screening in hyperechogenic fetal bowel, since one CF case was diagnosed prenatally per 35 fetuses tested. Ultrasound screening resulted in an acceptable detection rate (6/7). None of the children with no CFTR mutations identified prenatally developed clinical symptoms of CF postnatally. However, we are aware that the generalisation of our results should take into account the incidence of $C F$ in the population screened and the variation in $\mathrm{CF}$ mutations according to ethnic background.

The major drawback of CF screening in fetuses with hyperechogenic bowel is in generating parental anxiety, especially when the fetus is found to be heterozygous for a CFTR mutation. In this situation, it is difficult to evaluate accurately the risk of misdiagnosing a rare mutation in the other apparently normal chromosome. The number of mutations screened for is an intrinsic limitation of this approach to prenatal genetic screening. Increasing the number of mutations tested in heterozygous cases is desirable but will only partly reduce the risk of false negatives. Indeed, even extensive DNA screening based on DGGE may give ambiguous results since a new polymorphism within the CFTR gene may be impossible to distinguish from an as yet unreported pathogenic mutation.

Not surprisingly, 15 of the 209 fetuses tested were found to be heterozygous, which is not significantly different from the frequency of heterozygous CF (5\%) calculated from postnatal studies in France. ${ }^{17}$ Since only 1/15 heterozygous survivors developed $\mathrm{CF}$, we advocate that conservative management should be offered in such cases.

Although not observed in this series, CF resulting from two rare mutations cannot be firmly excluded. As previously described, ${ }^{10}$ it is very important to specify the high rate of adverse pregnancy outcomes, which may approach $20-25 \%$, as a result of CF but also congenital anomalies, chromosomal abnormalities, congenital infections, and intrauterine fetal death (probably secondary to placental haemorrhage).

In conclusion, we believe that $\mathrm{CF}$ screening based on ultrasound detection of hyperechogenic bowel is effective, especially in populations where $\mathrm{CF}$ is frequently observed. However, we are aware that this approach has intrinsic limitations because fetal sonography is implemented relatively late in gestation, and because the definition of bowel hyperechogenicity is somewhat subjective. ${ }^{12}$ However, the prenatal identification of fetal hyperechogenic bowel is now a matter of fact in clinical practice, and our results provide an objective basis for review of genetic counselling in this novel situation of the fetus being the index case for a genetic disease. However, a prospective study needs to be undertaken in order to estimate CF frequency among fetuses without echogenic bowel and the sensitivity of ultrasound evaluation as a tool for CF screening.

1 Fakhry J, Reiser M, Shapiro LR, Schechter A, Pait LP, Glennon A. Increased echogenicity in the lower fetal abdomen: a common normal variant in the second trimester. men: a common normal variant in

2 Manco LG, Nunan FA, Sohnen H, Jacobs EJ. Fetal small bowel simulating an abdominal mass at sonography. $\mathcal{F}$ Clin Ultrasound 1986;14:404-7.

3 Parulekar SG. Sonography of normal fetal bowel. $f$ Ultrasound Med 1991;10:210-11.

4 Bromley B, Doubilet P, Frigoletto F, Krauss C, Estroff J, Benaceraf B. Is fetal hyperechoic bowel on secondtrimester sonogram an indication for amniocentesis? Obstet Gynecol 1994;83:647-51.

5 Corteville JE, Gray DL, Langer JC. Bowel abnormalities in the fetus - correlation of prenatal ultrasonographic findings with outcome. Am f Obstet Gynecol 1996;175:724-9.

6 Blumenthal DH, Rushovich AM, Williams RK, Rochester D. Prenatal sonographic findings of meconium peritonitis with prenatal sonographic findings of meconium peritonitis with

7 Lince DM, Pretorius DH, Manco-Johnson ML, ManchesLince DM, Pretorius DH, Manco-Johnson ML, Manches-
ter D, Clewell WH. The clinical significance of increased ter D, Clewell WH. The clinical significance of increased
echogenicity in the fetal abdomen. AfR 1985;145:683-6. echogenicity in the fetal abdomen. $A F R$ 1985;145:683-6.
Nyberg DA, Resta RG, Luthy DA, Hickok DE, Mahony BS Hirsch JH. Prenatal sonographic findings of Down syndrome: review of 94. Obstet Gynecol 1990;76:370-7.

9 Forouzan I. Fetal abdominal echogenic mass: an early sign of intrauterine cytomegalovirus infection. Obstet Gynecol 1992; 80:535-7.

10 Muller F, Dommergues M, Aubry MC, et al. Hyperechogenic fetal bowel: an ultrasonographic marker for adverse fetal and neonatal outcome. Am 7 Obstet Gynecol 1995;173. 508-13.

11 Stringer MD, Thornton JG, Mason GC. Hyperechogenic fetal bowel. Arch Dis Child 1996;74:F1-2. 
12 Slotnick RN, Abuhamad A. Prognostic implications of fetal echogenic bowel. Lancet 1996;347:85-7.

13 Muller F, Frot JC, Aubry MC, Boué J, Boué A. Meconium ileus in cystic fibrosis fetuses. Lancet 1984;ii: 223.

14 Bahado-Singh R, Morotti R, Copel JA, Mahoney MJ. Hyperechoic fetal bowel: the perinatal consequences. Prenat Diagn 1994;14:981-7.

15 Hill LM, Fries J, Hecker J, Grzybek P. Second-trimester echogenic small bowel: an increased risk for perinatal outcome. Prenat Diagn 1994;14:845-50.

16 MacGregor SN, Tamura R, Sabbagha R, Brenhofer J Kambich MP, Pergament E. Isolated hyperechoic fetal bowel: significance and implications for management. Am $\mathcal{f}$ Obstet significance and implication

17 Simon-Bouy B, Mornet E, Serre JL, Taillandier A, Boué J, Boue $\mathrm{A}$. The cystic fibrosis delta F508 mutation in the French population. Hum Genet 1990;85:431-2.

18 Doherty RA, Bradley LA, Haddow JE. Prenatal screenin for cystic fibrosis: an updated perspective. Am $\mathcal{f}$ Obstet Gynecol 1996;176:268-70.
19 Férec C, Audrezat MP, Mercier B, et al. Detection of over $98 \%$ cystic fibrosis mutations in a Celtic population. Nat Genet 1992;1:188-91.

20 Asch DA, Patton JP, Hershey JC, Mennuti MT. Reporting the results of cystic fibrosis carrier screening. Am $\mathcal{F}$ Obstet Gynecol 1993;168:1-6.

21 Brambati B, Tului L, Fattore S, Ferec C. First-trimester fetal screening of cystic fibrosis in low risk population. Lancet 1993;342:624.

22 Livingstone J, Axton RA, Gilfillan A, et al. Antenatal screening for cystic fibrosis: a trial of the couple model. $B M \mathcal{F}$ 1994;8:1459-62.

23 Lieu TA, Watson SE, Washington AE. The costeffectiveness of prenatal carrier screening for cystic fibrosis. Obstet Gynecol 1994;84:903-12.

24 Brock DJH. Heterozygote screening for cystic fibrosis. Eur $\mathcal{F}$ Hum Genet 1995;3:2-13.

25 Schwimer SR, Vanley GT, Reinke RT. Prenatal diagnosis of cystic meconium peritonitis. $\mathcal{F}$ Clin Ultrasound 1984;12: 37-9. 